\title{
OS HERÓIS DE BRUMADINHO: O SUPORTE ESTATAL AOS BOMBEIROS DECORRENTES AO MAIOR DESASTRE HUMANITÁRIO DE MINAS GERAIS
}

PEDRO HENRIQUE DE ALMEIDA MENDES Graduando em Direito, modalidade integral, na Escola Superior Dom Helder Câmara. Belo Horizonte - MG. E-mail: pham1912@gmail.com.

\section{CAIO AUGUSTO SOUZA LARA}

Mestre e Doutor em Direito pela Faculdade de Direito da Universidade Federal de Minas Gerais - UFMG. Professor da Escola Superior Dom Helder Câmara. Pesquisador Associado ao Programa RECAJ-UFMG - Acesso à Justiça e Solução de Conflitos. Secretário de Comunicação do Conselho Nacional de Pesquisa e Pósgraduação em Direito - CONPEDI. Belo Horizonte-MG. E-mail: caiolarabh@yahoo.com.br.

\section{RESUMO}

O tema-problema da pesquisa que se pretende desenvolver é o descaso estatal quanto ao suporte psicossocial dos membros do Corpo de Bombeiros de Minas Gerais no acontecimento conhecido como desastre de Brumadinho. Foram mais de 6 milhões de centímetros cúbicos de lama despejados pela barragem, o que gerou os lamentáveis 218 óbitos e mais de 70 desaparecidos e a maior operação de salvamento e resgate de corpos da história brasileira. É evidente que uma operação deste porte acarreta tensões psicológicas severas aos militares envolvidos, principalmente pela razão deles em lidarem frequentemente com restos corporais em decomposição durante suas buscas. É também claro os diversos problemas que o contato direto com a lama pode trazer ao indivíduo, podendo ser irreversíveis. Em 


\section{Personalidade Acadêmica Homenageada:}

Raymundo Juliano Feitosa (Universidade Federal do Rio Grande do Norte - UFRN)

alguns casos, esses metais jamais sairão do organismo do infectado e, no maior dos problemas, pode levar até mesmo ao óbito. Segundo o jornal Folha de São Paulo, "já se tem 4 militares infectados por metais pesados advindos do contato com a lama da barragem de Brumadinho". Assim, percebe-se que os bombeiros envolvidos no desastre não têm o devido suporte estatal. Em exatos 42 dias antes do desastre, foi concluído um curso sobre salvamento em soterramento, enchentes e inundações, sob comando do capitão Leonardo Fará. Porém, apenas 36 soldados concluíram esse curso, que foi iniciado em 2014 por 46 militares e cerca de 360 bombeiros trabalharam na operação. O problema objeto da investigação científica proposta é: qual apoio os bombeiros têm e quais os direitos, enquanto servidores públicos, foram violados ao atuarem no desastre de Brumadinho? A partir das reflexões preliminares sobre o tema, é possível afirmar inicialmente que o apoio do Estado para os bombeiros quanto aos problemas psicológicos, físicos e outras enfermidades é escasso. Tal fato acarreta na reflexão acerca dos direitos humanos vilipendiados e que deveriam ser assegurados pelo próprio órgão que desconsidera esse direito, o órgão público. Desse modo, esse direito deve ser dado a esses indivíduos, mas sem perder a ciência de que esta profissão (de bombeiros) naturalmente já requer um certo risco a quem trabalha com ela. $O$ objetivo geral do trabalho é evidenciar qual o apoio que os bombeiros têm a fim de manter suas saúdes devidamente adequadas. A pesquisa que se propõe pertence à vertente metodológica jurídico-sociológica. No tocante ao tipo de investigação, foi escolhido, na classificação de Witker (1985) e Gustin (2010), o tipo jurídico-projetivo. raciocínio desenvolvido na pesquisa será predominantemente dialético. De acordo com a técnica de análise de conteúdo, afirma-se que se trata de uma pesquisa teórica, o que será possível a partir da análise dos fatos ocorridos com os militares, normas e demais dados colhidos na pesquisa. A partir do texto exposto conclui-se preliminarmente que apesar dos bombeiros terem recebido apoio estatal e por parte da empresa de mineração VALE, é notório que os bombeiros continuam não só suscetíveis a riscos, como estão registradas infecções e contaminação a alguns militares. Assim, os suportes recebidos claramente são supérfluos ou ineficazes para a manutenção da integridade física e psicológica desses indivíduos. A partir dessa 
Personalidade Acadêmica Homenageada:

Raymundo Juliano Feitosa (Universidade Federal do Rio Grande do Norte - UFRN)

análise, é evidente a necessidade de se atentar para tal fato e buscar intervenções eficazes que resguardem a vida com condições de plena saúde dos bombeiros envolvidos na operação de busca em Brumadinho e, designar a esses militares, direitos básicos existentes no direito do trabalho, como a remuneração por insalubridade, que não ocorre aos bombeiros, mesmo sabendo das condições de grandes riscos que eles correm e o direito que deveria ser assegurado, por ele ser reportado na lei.

PALAVRAS-CHAVE: Corpo de Bombeiros; Suporte; Brumadinho; Desastre; Barragem.

\section{REFERÊNCIAS}

ANIZELLI, Eduardo. Exames de bombeiros que trabalham em Brumadinho apresentam alteração para metais. Folha de São Paulo. Disponível em: https://www1.folha.uol.com.br/cotidiano/2019/02/exames-de-bombeiros-quetrabalham-em-brumadinho-apresentam-alteracao-para-metais.shtml. Acesso em: 05/05/2019.

BRASIL. Constituição da República Federativa do Brasil de 1988. Brasília:Senado,1988. Disponível em: https://edisciplinas.usp.br/mod/book/view.php?id=45199\&amp;chapterid=365\&gt;. Acesso em:06/05/2019.

DUTRA, Pedro. Entrevista: Pedro Dutra. (S.1): Estudante de Relações Internacionais, mar.2019. Entrevista concedida a Pedro Henrique de Almeida Mendes.

FARÁ, Leonardo. Belo Horizonte MG: Coração de Bombeiro - Operações em Desastres. Youtube, 09 de fev. de 2019. Disponível em: \&lt;https://youtu.be/Jwwio4qJG9o\&gt;. Acesso em: 01 maio 2019.

GUSTIN, Miracy Barbosa de Sousa; DIAS, Maria Tereza Fonseca. (Re)pensando a pesquisa jurídica: teoria e prática. $3^{a}$. ed. Belo Horizonte: Del Rey, 2010.

MOREIRA, Renan Lúcio. Licenciamento ambiental e a política nacional de segurança de barragem. ISSN:2316-753X. Revista Jurídica - UNICURITIBA, Curitiba, V.03, n.48, p.271-298. 2017. Disponível em: 
Personalidade Acadêmica Homenageada:

Raymundo Juliano Feitosa (Universidade Federal do Rio Grande do Norte - UFRN)

http://revista.unicuritiba.edu.br/index.php/RevJur/article/view/2181. Acesso em: 20 maio 2019.

O QUE SÃO metais pesados e porque fazem mal á saúde. Portal Super Interessante - 18 abr. 2011. Disponível em:https://super.abril.com.br/mundoestranho/o-que-sao-metais-pesados-e-por-que-fazem-mal-a-saude/. Acesso em: 03 maio 2019.

PINTO, Vanessa. Segurança do Trabalho: O que é insalubridade?. Jusbrasil. Disponível em: https://vanessadeandradepinto.jusbrasil.com.br/artigos/510346398/seguranca-dotrabalho-o-que-e-insalubridade. Acesso em: 02 maio 2019.

TANAKA, Werner. Entrevista: Werner Tanaka. (S.1): Bombeiro Militar, mar.2019. Entrevista concedida a Pedro Henrique de Almeida Mendes.

WITKER, Jorge. Como elaborar uma tesis en derecho: pautas metodológicas y técnicas para el estudiante o investigador del derecho. Madrid: Civitas, 1985. 